\title{
O discurso jornalístico impresso e o "espetáculo" da democracia
}

\author{
Fábio Fernando Lima \\ Pontifícia Universidade Católica do Rio de Janeiro (PUC/Rio), \\ Rio de Janeiro, Rio de Janeiro, Brasil \\ fábiofernandolima@uol.com.br
}

DOI: http://dx.doi.org/10.21165/el.v46i3.1564

\begin{abstract}
Resumo
Neste artigo, buscaremos apresentar os resultados de um estudo que se propõe a investigar, analisar e descrever as estruturas responsáveis pelo estabelecimento das relações interpessoais e as intersecções destas com a persuasão no noticiário de jornais paulistas, estabelecendo, como recorte, publicações relacionadas aos desdobramentos da crise política no Brasil. Sustentaremos que o processo contemporâneo de "politização das mídias", relativo ao fato de as mídias passarem a se apresentar pretensamente como instituições que cumprem uma função social imprescindível, propriamente a de desvelar criticamente aquilo que estaria oculto no mundo político, emerge na materialidade discursiva por meio de diversas estratégias camufladas de persuasão e controle. Construindo a ilusão da objetividade e imparcialidade, essas estratégias fortalecem a imposição de determinadas ideologias e o estabelecimento de consensos hegemônicos.
\end{abstract}

Palavras-chave: persuasão; relações interpessoais; Análise Crítica do Discurso.

\section{The printed journalistic discourse and the "spectacle" of democracy}

\begin{abstract}
In this article, we try to present the results of a research that aims at investigating, analyzing and describing the structures responsible for the establishment of interpersonal relationships and their intersections with persuasion in Sao Paulo newspaper reports establishing as a particular approach publications related to unfolding political crisis in Brazil. We will argue that the contemporary process of "politicization of media" on the fact that the media go to perform supposedly as institutions that fulfill a vital social function, properly the critically reveal what was hidden in the political world, emerges in discursive materiality by through various strategies different camouflage of persuasion and control. Building the illusion of objectivity and impartiality, these strategies strengthen the enforcement of certain ideologies and the establishment of hegemonic consensus.
\end{abstract}

Keywords: persuasion; interpersonal relationship; Critical Discourse Analysis.

\section{Introdução}

A instalação definitiva da sociedade do espetáculo - vigente nos últimos quarenta anos, acompanhando as características das sociedades pós-modernas, caracterizadas pela radicalização dos traços da modernidade - reserva, ao discurso político veiculado pelas mídias, facetas um tanto distintas da materialização observada nos períodos anteriores. Em verdade, a política "espetacularizou-se", inseriu-se nos padrões midiáticos pósmodernos: se, até então, o discurso político era longo, mas crível, torna-se simulante (pois 
faz aparecer aquilo que não é) e dissimulante (por fazer não aparecer aquilo que é), construindo, respectivamente, os efeitos de sentido de mentira e segredo.

As mídias passam então a se apresentar pretensamente como instituições que cumprem uma "função social imprescindível, propriamente a de desvelar criticamente as mentiras e os segredos políticos" (PIOVEZANI FILHO, 2003, p. 54):

[...] visualiza-se, pois, a atuação da mídia, em função de sua suposta "politização", como "porta-voz" daqueles que já alijados do poder (que, paradoxalmente, eles mesmos concederam), impossibilitados de agir efetivamente no espaço político, devem contentarse com a mera assistência do desenrolar das ações ali empreendidas (PIOVEZANI FILHO, 2003, p. 58).

Nesse contexto, as mídias se apresentam como organismos especializados que têm a vocação de responder a uma demanda social por dever de democracia, atribuindo, assim, aos jornalistas, o papel de agentes que buscam tornar público aquilo que seria ignorado, oculto ou secreto, "em benefício da cidadania". Conforme bem aponta Charaudeau (2006, p. 17), "enquanto se admite no mundo político, de maneira geral, que o discurso aí manifestado está intimamente ligado ao poder e, por conseguinte, à manipulação, o mundo das mídias tem a pretensão de se definir contra o poder e contra a manipulação". No entanto, de acordo com o autor, o poder da instância midiática reside, justamente, no fato de as mídias não transmitirem o que ocorre na realidade social, mas imporem o que constroem do espaço público. Tomando-se a informação enquanto uma questão essencialmente de linguagem, e o fato de a linguagem, por seu turno, não ser transparente ao mundo, mas representar a construção de uma visão, de um sentido particular do mundo, temos, por conseguinte, que as mídias não são a própria democracia, mas "o espetáculo da democracia".

A preocupação com a manipulação nesses contextos ganha respaldo quando tomada em consideração a posição assumida por Van Dijk (2008, p. 73) que, assentada nos trabalhos empreendidos por Robinson e Levy (1986 apud VAN DIJK, op. cit.) e Bruhn Jensen (1986 apud VAN DIJK, op. cit.), afirma: "ao contrário da crença popular e do senso comum entre os estudiosos, as notícias na imprensa escrita são mais bem lembradas que as notícias na televisão e são percebidas como qualitativamente superiores, o que pode ampliar sua influência persuasiva e, portanto, seu poder”. Em verdade, essa preocupação tem a ver com o controle exercido pelos grandes conglomerados empresariais que administram os jornais sobre a formação da opinião pública. Assim, se por um lado, as mídias se apresentam como um organismo especializado que tem a vocação de responder a uma demanda social "por dever de democracia", elas também se encontram, por outro lado, concentradas nas mãos das classes dominantes, interessadas em exercer o controle ideológico sobre as classes dominadas, mantendo o status quo.

Partindo da análise da configuração contemporânea do mundo social, Marshall (2003, p. 23) afirma que "o jornalismo é a linguagem que codifica e universaliza a cultura hegemônica e legitima a lógica do mercado", o que fundamenta o interesse de tantos pesquisadores oriundos dos mais diversos campos do conhecimento. Os meios de comunicação produzem e difundem bens simbólicos, como propõe Thompson (1998), de maneira a assumir papel preponderante na divulgação de ideias e, ao mesmo tempo, enorme influência na esfera do Novo Capitalismo. 
É indiscutível que os textos veiculados pelas mídias apresentam visões do mundo social, legitimando as posições daqueles que mais lhe interessam por meio da reprodução ou transformação dos fatos a serem noticiados. A essas transformações e suas consequências, Castells (2008, p. 336) denomina "política informacional", caracterizando-as por reconfigurar o debate político e as estratégias de busca de poder. Para o autor, a mídia, seja ela impressa ou eletrônica, é o espaço onde se travam as lutas políticas e "sem ela, não há meios de adquirir ou exercer poder" (CASTELLS, 2008, p. 367).

Para Charaudeau (2006, p. 221), "a reportagem jornalística trata de um fenômeno social ou político, tentando explicá-lo". Nesse processo, espera-se sempre do jornalista uma reportagem que esteja mais próximo possível da realidade do fenômeno a ser retratado e, ao mesmo tempo, "que demonstre imparcialidade, isto é, que sua maneira de perguntar e de tratar as respostas não seja influenciada por seu engajamento, por se tratar de um jornalista" (CHARAUDEAU, 2006, p. 222). No entanto, o autor assinala ser essa tarefa impossível, porque a construção de sentido depende da adoção de um ponto de vista particular, o que torna a parcialidade inclusive necessária: todo procedimento de análise implica, enfim, tomada de posição.

Nesse sentido, a mídia, de modo geral, transforma um acontecimento em notícia interpretada por um jornalista que organiza seu discurso de acordo com o público-alvo do jornal em que trabalha. Ademais, o jornalista escreve tanto como representante profissional de determinada instituição de comunicação quanto como membro de um determinado grupo social, postura esta que, conforme assinala Van Dijk (2008), molda suas cognições sociais, suas ideologias e, por conseguinte, o processamento de informações acerca do fato a ser noticiado. Esse discurso, muitas vezes camuflado por meio de diversas estratégias, corresponde à possibilidade de se propagar uma crença, legitimando o poder dos grupos dominantes.

A perspectiva que atribui ao jornalista um lugar de destaque nas estruturas de poder ideológico da sociedade moderna encontra respaldo em Bourdieu (1991). Para o autor, os jornalistas pertencem às chamadas "elites simbólicas", detentoras do "capital simbólico", responsáveis pelo controle dos modos de produção e articulação da fala e escrita públicas. Por possuírem relativa liberdade, detêm poder para tomar decisões sobre gêneros textuais dentro de seu domínio e de determinar tópicos, estilo ou forma de apresentação de um discurso.

Conforme destaca Van Dijk (2008, p. 45), os jornalistas são "os fabricantes do conhecimento, dos padrões morais, das crenças, das atitudes, das normas, das ideologias e dos valores públicos. Portanto, seu poder simbólico é também uma forma de poder ideológico".

Neste artigo, buscaremos apresentar os resultados de um trabalho que visa a analisar e descrever as estruturas responsáveis pelo estabelecimento das relações interpessoais e as intersecções destas com a persuasão no noticiário político contemporâneo, observando a manifestação de ideologias e a busca pelo estabelecimento de determinados consensos. Para a operacionalização dessa tarefa, partimos dos estudos desenvolvidos no âmbito da Análise Crítica do Discurso (ACD), em especial do modelo tridimensional apresentado por Fairclough $(1997,2001,2007)$ e suas variações, e buscamos, paralelamente, amalgamar tais estudos à Retórica, em especial à Nova 
Retórica de Perelman e Olbrechts-Tyteca (1996), assumindo como premissa que a persuasão constitui-se na maneira mais eficiente de exercício de poder.

\section{A opção pela Análise Crítica do Discurso}

Para efeitos da pesquisa que aqui delineamos, partimos do princípio de que uma atividade de produção textual completamente isenta de posições subjetivas esbarra nas próprias condições de produção do texto. Isso porque, de acordo com a vertente teórica que fundamenta este trabalho, propriamente a Análise Crítica do Discurso, os sentidos não são dados a priori, mas construídos por indivíduos ou grupos que, enquanto sujeitos sócio-históricos, elaboram e interagem com textos produzidos a partir de contingências atreladas a estruturas e processos sociais, dos quais tomam parte ${ }^{1}$.

De um modo geral, a ACD apresenta-se como um campo de investigação interessado em propor uma teoria e um método para descrever, interpretar e explicar as relações estruturais, transparentes ou veladas, de poder e controle manifestos na linguagem (cf. WODAK, 2004). Assume-se, como ponto central, a análise das maneiras pelas quais "o discurso contribui para a reprodução da desigualdade e da injustiça social, determinando quem tem acesso a estruturas discursivas e de comunicação aceitáveis e legitimadas pela sociedade" (VAN DIJK, 1994, p. 4-5).

Considerando os grupos dominantes como aqueles que detêm o controle dos grandes veículos de comunicação, bem como o acesso à manipulação e ao uso de estratégias discursivas de dominação, em um cenário no qual a linguagem ocupa o centro do modo de produção do sistema capitalista (cf. HABERMAS, 1984), tem-se, de acordo com Van Dijk (1994, p. 6), que

O discurso e a comunicação se convertem então nos recursos principais dos grupos dominantes. Por meio de um estudo do discurso, pode-se conseguir compreender os recursos de dominação utilizados pelas elites, pois estas têm um controle específico sobre o discurso público. É um poder que permite controlar os atos dos demais, define quem pode falar, sobre o que e quando. Considero que o poder das elites é um poder discursivo uma vez que, por meio da comunicação, há o que se denomina "uma manufatura do consenso": trata-se de um controle dos atos linguísticos por meio da persuasão, a maneira mais moderna e última de exercer o poder. Os atos são intenções e, controlando as intenções, se controlam, por sua vez, os atos. Existe então um controle mental através do discurso.

Esse segmento permite que observemos uma integração entre a ACD e a Retórica, que está colocada como "a maneira mais moderna de exercício do poder". O autor considera que, por meio da persuasão e manipulação, dominam-se as mentes das pessoas, as quais, por sua vez, controlam as ações. Em suas palavras,

[...] o poder moderno é aquele que se exerce por meio do controle mental, maneira indireta de controlar os atos dos outros. O poder moderno consiste em influenciar os outros por meio da persuasão para conseguir que façam o que se quer. Os grupos que têm acesso a essas formas de poder e controle são geralmente aqueles que têm sido legitimados e têm

\footnotetext{
${ }^{1}$ Faz-se necessário ressaltar que esta posição é sustentada pelo ponto de vista teórico que embasa esta pesquisa em particular, não sendo, de longe, exclusiva.
} 
acesso ao discurso público. [...] O discurso é poder e a persuasão é o maior controlador dos atos linguísticos na modernidade (VAN DIJK, 1994, p. 10-11).

No entanto, apesar de toda a importância conferida à argumentação, não encontramos, na literatura corrente, um modelo capaz de amalgamar definitivamente os aspectos retóricos com a análise e interpretação da linguagem em contexto sóciohistórico. É visando a suprir essa lacuna que propomos, para a abordagem da persuasão no noticiário da imprensa escrita paulista acerca dos desdobramentos da crise política no Brasil, estabelecer pontos de contato entre a Teoria Social do Discurso, elaborada por Fairclough (1997, 2007), e a Nova Retórica de Perelman e Olbrechts-Tyteca (1996).

Tendo em vista a constituição de uma abordagem teórica multidirecional capaz de sintetizar, ao mesmo tempo, as concepções de discurso com orientação social e linguística, Fairclough faz uso, no que se refere à orientação linguística de sua teoria, da Linguística Sistêmico Funcional de Halliday (2001).

$\mathrm{Na}$ realidade, Fairclough (2007) concebe o discurso como uma prática social inserida em uma estrutura social mais ampla, materializado por textos que podem cumprir determinadas finalidades, tais como mudanças nos sistemas de conhecimentos, crenças, posicionamentos, valores, tanto no que se refere aos atores sociais em atividade discursiva quanto no que diz respeito ao mundo material. Evoca, dessa maneira, uma perspectiva funcionalista da linguagem, na medida em que esta postula que a língua possui funções externas ao sistema e que tais funções são as responsáveis pela organização interna do sistema linguístico.

De acordo com Fairclough (2001), pode-se distinguir três aspectos construtivos do discurso: a construção das identidades sociais e posições do sujeito; a construção das relações sociais entre as pessoas e, por fim, de sistemas de conhecimento e crenças. Em suas palavras

[...] esses três efeitos correspondem respectivamente a três funções da linguagem e a dimensões de sentido que coexistem e interagem em todo discurso - o que denominarei as funções da linguagem 'identitária', 'relacional' e 'ideacional'. A função identitária relaciona-se aos modos pelos quais as identidades sociais são estabelecidas no discurso, a função relacional a como as relações sociais entre os participantes do discurso são representadas e negociadas, a função ideacional aos modos pelos quais os textos significam o mundo e seus processos, entidades e relações. As funções identitária e relacional são reunidas por Halliday como a função interpessoal (FAIRCLOUGH, 2001, p. 91-92).

Cumpre registrar que Halliday (2001), ao analisar a língua em situação de uso, alia contexto e estrutura social à produção discursiva mediante três metafunções derivadas do contexto, propriamente campo, relação e modo, definidas, respectivamente, de uma maneira muito geral, como a atividade em que os participantes estão engajados, os próprios participantes e as relações estabelecidas entre eles e as maneiras pelas quais os significados são realizados - significados que atualizam as funções ideacional, interpessoal e textual no discurso.

Fairclough $(1997,2001,2007)$ reformula a teoria hallidayana de acordo com os parâmetros da $\mathrm{ACD}$, concebendo o discurso como um nível intermediário entre o texto em si e o contexto/estrutura social, atravessado por gêneros (modos de agir), estilos (modos de ser) e discursos (modos de representar) específicos. Assim, os gêneros 
relacionam-se à função textual e à função interpessoal de Halliday (op. cit.), no que tange ao estabelecimento de relações sociais; os estilos abarcam o aspecto de construção de identidades subjetivas no discurso, o que também integra a função interpessoal; e os discursos ou representações equivalem à função ideacional ${ }^{2}$.

Nessa perspectiva, os discursos, como elementos de representação e, portanto, campo do desenvolvimento ideológico, instanciam gêneros e estilos determinados, que, por sua vez, são representados em discursos, configurando uma relação dialética entre esses elementos.

Para efeitos deste trabalho, iremos nos deter nos aspectos interpessoais das notícias analisadas e buscaremos relacioná-los ao desencadeamento de determinadas estratégias argumentativas, as quais estão devidamente elencadas no Tratado da Argumentação (cf. PERELMAN; OLBRECHTS-TYTECA, 1996). Isso porque tais categorias permitem observar exatamente as maneiras pelas quais o jornalista/escritor, inserido em um determinado contexto sócio-cognitivo, tanto atribui determinadas identidades sociais aos atores designados em seu texto quanto expressa seus posicionamentos e julgamentos, buscando, sempre, de acordo com as premissas aqui assumidas, influenciar e levar o leitor a assumir esse mesmo ponto de vista. É por meio da função interpessoal que são instanciadas as relações pessoais e sociais dos participantes dos eventos discursivos, tanto no aspecto de sua configuração identitária quanto da sua relação com os outros atores sociais envolvidos no processo.

No que diz respeito ao que foi descrito no parágrafo anterior, faz-se importante acrescentarmos que os estudos englobados pela ACD valem-se não apenas dos aspectos gramaticais concernentes ao modo e modalidade estabelecidos por Halliday (2001) para a mencionada função, mas também das contribuições advindas de outros estudiosos que têm trabalhado de perto com a proposta hallidayana, os quais não apenas aplicaram essa teoria, mas também a complementaram ou, inclusive, participaram de sua elaboração. No entanto, para a pesquisa que aqui delineamos, levaremos em conta a proposta de análise apresentada por Martin e White (2005), cujo mérito reside em sintetizar todos esses estudos e propor uma categorização ainda mais abrangente dos mecanismos linguísticos acionados para o estabelecimento das relações interpessoais.

Partindo do modelo apresentado por Fairclough e buscando justamente integrar a metafunção interpessoal da teoria hallidayana à Análise Crítica do Discurso, os autores apresentam uma proposta centrada na abordagem da valoração, instrumentalizada com vistas a analisar, de forma sistemática, como a avaliação e a perspectiva operam em textos. De acordo com White (2004, p. 177),

[...] a abordagem está interessada nas funções sociais desses recursos, não simplesmente como formas através das quais falantes/escritores individuais expressam seus sentimentos e posições, mas como meios que permitem que os indivíduos adotem posições de valor determinadas socialmente, e assim se filiem, ou se distanciem, das comunidades de interesse associadas ao contexto comunicacional em questão.

Dessa maneira, tais estudos se voltam para a constituição de categorias sóciosemióticas relacionadas à construção da intimidade, da distância, do envolvimento, da

\footnotetext{
${ }^{2}$ Para o autor, a transitividade verbal está vinculada à representação das ideias ou experiências humanas e, por isso mesmo, constitui-se no elemento característico para análise do componente ideacional.
} 
identidade e da autoridade discursivas, realizadas, linguisticamente, por meio de recursos avaliativos. Segundo os autores, a atitude, o engajamento e a gradação podem ser concebidos como fenômenos linguísticos que atualizam posicionamentos intersubjetivos dos atores sociais em interação.

De acordo com esse ponto de vista, a atitude abrange significados graduáveis por meio dos quais o falante/escritor avalia entidades, estados de coisas e acontecimentos negativa ou positivamente. É subdividida em afeto (reações afetivas diante de uma situação ou comportamento específico), julgamento (avaliações acerca da capacidade, normalidade, tenacidade, propriedade e veracidade dos comportamentos ou atitudes humanas e/ou institucionais) e apreciação (avaliações de caráter estético acerca de elementos concretos da realidade, como objetos, ou de risco e importância, no que tange a nominalizações - processos, eventos, entidades abstratas).

A gradação, por seu turno, está relacionada aos modos pelos quais os falantes/escritores maximizam ou minimizam a força de suas asserções, tornando nítidas ou ofuscadas as categorizações semânticas com as quais operam. O engajamento, por fim, constitui-se no componente por meio do qual o autor se posiciona em relação a seu enunciado e aos enunciados potenciais de outros atores sociais envolvidos na interação. Como centro dessas categorias, está a ideia de que todo enunciado é visto como posicionado. Trata-se de uma categoria calcada na noção de heteroglossia ou heterogeneidade constitutiva do círculo bakhtiniano, por meio da qual se objetiva descrever em que medida falantes/escritores avaliam as afirmações anteriores, qual o peso dessas afirmações em suas formulações e de que modo eles se engajam em relação a tais enunciados (em oposição, concordância, etc.) ${ }^{3}$.

No entanto, Martin e White (2005) admitem que, para que o produtor do texto adquira, eficientemente, o comprometimento dos leitores e ouvintes, além das categorias apontadas, ele precisará contar com os argumentos dispostos e o processo persuasivo de maneira geral, embora esse aspecto não seja explorado pelos autores.

É visando a propor um enfoque mais amplo e adequado que buscaremos, ao analisar o noticiário político contemporâneo, observar como são processadas tais categorias e, paralelamente, apontar as maneiras pelas quais cada um desses elementos, responsáveis por ativar relações interpessoais com o leitor, acionam e se entrelaçam a determinadas estratégias argumentativas. Para o desenvolvimento dessa tarefa, levamos ainda em consideração os estudos acerca da argumentação, particularmente aqueles que se apresentam como desdobramentos contemporâneos da Velha Retórica aristotélica, conforme se poderá observar na próxima seção.

\section{Análise dos dados}

Se as longas narrativas relacionadas aos atos de campanha e discursos operados pelos candidatos permeiam o noticiário do jornalismo impresso brasileiro da segunda metade do século XIX e início do século XX, são as formas mais curtas, verificadas a

\footnotetext{
${ }^{3}$ Apesar de não apresentar uma categorização propriamente dita, Van Dijk (2008, p. 52-53) adota um ponto de vista muito semelhante. Analisando as reportagens jornalísticas, o autor afirma que as mesmas não apenas descrevem os eventos atuais e suas possíveis consequências, mas também procuram apresentar "cursos alternativos e indesejáveis da ação", avaliando e, assim, buscando influenciar, pela via persuasiva, a ação futura dos indivíduos.
} 
partir dos anos 50, que se impõem diacronicamente (cf. LIMA, 2013). Isso porque, conflagrada a inserção definitiva do discurso político veiculado pelas mídias na sociedade do espetáculo, as formas didáticas da retórica política clássica são substituídas por formas novas, que submetem os conteúdos políticos às exigências de escrita e leitura próprias aos novos imperativos dos veículos de comunicação.

Essa nova caracterização do discurso político veiculado pelas mídias está intrinsecamente ligada às transformações sofridas pelo auditório dos oradores políticos. $\mathrm{Na}$ realidade, o orador tradicional encontrava sua dimensão verdadeira no ajuntamento popular: distante, quase nunca visível, ele estava, entretanto, em contato com cada um, quando todos estivessem reunidos. Se ele não era sempre visível, podia-se ouvi-lo. "Essa situação clássica de massa política, longamente analisada na virada do século $\mathrm{XX}$, tende a se rarear: as massas não se deixam mais reunir sobre a cena política. Elas aparecem somente de maneira imprevisível, onde não são esperadas" (COURTINE, 2003, p. 25).

A dissolução da massa política, contemporânea das tecnologias de comunicação de massa, implica que o orador político não seja mais ouvido, mas, sobretudo, visto ou lido em domicílio. A massa política dispersou-se, fragmentou-se e se compartimentou na intimidade das entrevistas e dos debates.

Se houve essa midiatização da política, pode-se pensar que houve um movimento complementar, o da "politização da mídia", cuja materialização mais evidente está, de acordo com Piovezani Filho (2003), na busca empreendida pela mídia para ocupar uma posição de agente político: "subsidiada na pretensa existência, no espaço político, de um nível profundo (e, por isso mesmo, mais real), ou de uma dupla dimensão - a da manifestação (aparência) e a da imanência (essência) -, a mídia reivindica a legitimidade de sua laboração politizada [...], a postura crítico-heurística que ela toma cumpre a função de deslindar o obtuso, de revelar o real" (PIOVEZANI FILHO, 2003, p. 57).

Além disso, considerando que o "capital político é uma forma de capital simbólico, crédito firmado na crença e no reconhecimento" (BOURDIEU, 2001, p. 187), sustenta-se que o espaço político torna-se amiúde vulnerável às suspeitas, às denúncias e aos escândalos. "Visualiza-se, pois, a atuação da mídia, em função de sua suposta "politização", como "porta-voz" daqueles que já alijados do poder (que, paradoxalmente, eles mesmos concederam), impossibilitados de agir efetivamente no espaço político, devem contentar-se com a mera assistência do desenrolar das ações ali empreendidas" (PIOVEZANI FILHO, op. cit., p. 58). Anuncia-se uma subjetividade consumidora, de modo que se estabelece, com efeito, na produção discursiva midiática, uma interpretação espectadora.

Cumpre abrirmos aqui um breve parêntese para fazer referência aos critérios analíticos a serem empregados no exame do material, que passa a assumir papel central no trecho que segue. Em sintonia com os objetivos gerais do trabalho anteriormente descritos, faremos uso, por um lado, da proposta apresentada por Fairclough (1997, 2001, 2007) para a abordagem da metafunção interpessoal, complementando-a com a Teoria da Avaliatividade, elaborada por Martin e White (2005) e devidamente apresentada na seção anterior.

Tomando-se em consideração nosso interesse em amalgamar a análise e interpretação da linguagem em contexto sócio-histórico com a Retórica, associaremos esses recursos às "técnicas argumentativas" inventariadas por Perelman e OlbrechtsTyteca (1996) em sua obra. Trata-se de um inventário exaustivo de esquemas de 
argumentos, subdivididos em dois grandes grupos: os argumentos quase-lógicos e os argumentos baseados na estrutura do real. Os argumentos quase-lógicos são aqueles que se apresentam, ora de maneira implícita, ora de maneira explícita, como comparáveis a raciocínios formais, lógicos ou matemáticos. Muito embora os autores reconheçam que muitas outras relações poderiam ser examinadas, são subdivididos entre aqueles que apelam para estruturas lógicas - contradição, identidade total ou parcial, transitividade e aqueles que apelam para relações matemáticas - relação da parte com o todo, do menor com o maior e relação de frequência, além da comparação ${ }^{4}$.

Os argumentos baseados na estrutura do real, por sua vez, valem-se da relação mais ou menos estreita existente entre eles e certas fórmulas lógicas ou matemáticas para estabelecer uma solidariedade entre juízos estabelecidos e outros que se procura promover. Apesar de se classificarem conforme as estruturas do real às quais se aplicam e de poderem ser encontrados no uso comum, não se trata, conforme esclarecem Perelman e Olbrechts-Tyteca (op. cit.), de descrições objetivas do real, mas "da maneira pela qual se apresentam as opiniões a ele concernentes, podendo estas, aliás, serem tratadas, quer como fatos, quer como verdades, quer como presunções" (p. 298). São subdivididos entre argumentos que se aplicam a ligações de sucessão, que unem um fenômeno a suas consequências ou a suas causas - argumento pragmático, da direção, dentre outros - e argumentos que se aplicam a ligações de coexistência, que unem uma pessoa a seus atos, um grupo aos indivíduos que dele fazem parte e, em geral, uma essência a suas manifestações - por exemplo, o argumento de autoridade ${ }^{5}$.

Por fim, faremos as devidas ligações entre os resultados obtidos a partir da análise crítica do material e as ideologias atinentes, que aqui são entendidas enquanto efeitos de práticas sociais que incidem sobre a produção discursiva, direcionadas à imposição de determinados consensos hegemônicos.

Nos dias cruciais que embasaram a tomada de posição acerca do impeachment da Presidente da República do Brasil, Dilma Rousseff, emerge no jornal Folha de S. Paulo um vasto noticiário acerca dos desdobramentos da crise política no país, especialmente no que tange às operações empreendidas pela Polícia Federal e pela justiça que desvelavam o envolvimento oculto de políticos em esquemas de corrupção. Para o estudo que aqui desenvolvemos, em particular, trataremos do episódio da divulgação do grampo telefônico em que a Presidente conversa com seu antecessor, Luís Inácio Lula da Silva, acerca da entrega do termo de posse que instituiria Lula como Ministro da Casa Civil. Sob a ótica majoritária, a nomeação estaria vinculada a um objetivo oculto, propriamente o de afastar a investigação do ex-Presidente do foro de Curitiba e remetê-la ao STF.

Os fatos que se sucederam à divulgação da gravação ocuparam as manchetes de capa do jornal e foram tratados amiúde em diversas matérias, no decorrer de várias edições. A reiteração desses elementos, assentada na já mencionada função social imprescindivel assumida pelos jornais acerca do desvelamento das mentiras e segredos políticos, vai tecendo, estrategicamente, uma imagem negativa da Presidente da República. Observe:

\footnotetext{
${ }^{4}$ Em função dos limites aos quais está submetido este artigo, não nos deteremos na definição de cada tipo de argumento.

${ }^{5}$ Idem à nota anterior.
} 
O juiz federal Sérgio Moro incluiu no inquérito que tramita em Curitiba uma conversa telefônica entre o ex-presidente Lula e a presidente Dilma Rousseff, na qual ela diz que encaminhará a ele o "termo de posse" de ministro. Dilma diz a Lula que o termo de posse só seria usado "em caso de necessidade".

Os investigadores da Lava Jato interpretaram o diálogo como uma tentativa de Dilma de evitar uma eventual prisão de Lula. Se houvesse um mandado do juiz, de acordo com essa interpretação, Lula mostraria o termo de posse como ministro e, em tese, ficaria livre da prisão.

A informação foi revelada nesta quarta-feira (16) pelo canal "Globonews". A gravação ocorreu às $13 \mathrm{~h} 32$ desta quarta, quando Lula aceitou o convite para assumir a Casa Civil, no lugar de Jaques Wagner.

Segundo Moro, o telefone grampeado é de um assessor do Instituto Lula que era usado com frequência pelo ex-presidente. O juiz Moro não pode mandar prender ministros porque eles detêm foro privilegiado.

A conversa foi gravada pela Polícia Federal, no inquérito que apura a posse do sítio em Atibaia (SP). A hipótese dos investigadores é que o sítio foi doado a Lula por empresas que tinham contrato com a Petrobras, como a Odebrecht, OAS e José Carlos Bumlai, este amigo do ex-presidente. O Palácio do Planalto divulgou nota em que diz que a divulgação da gravação é uma "afronta aos direitos e garantias" da Presidência da República. "Todas as medidas judiciais e administrativas cabíveis serão adotadas para a reparação da flagrante violação da lei e da Constituição da República, cometida pelo juiz autor do vazamento", diz a nota.

O advogado de Lula, Cristiano Zanin Martins, acusa Moro de estimular uma "convulsão social" com a divulgação do telefonema. "Isso não é papel do Judiciário", disse.

Com a indicação de Lula à Casa Civil, o ex-presidente passa a ter foro privilegiado nas investigações da Lava Jato. Desta maneira, Lula só pode ser julgado pelo Supremo Tribunal Federal. No dia 4 de março, a Polícia Federal cumpriu um mandado de busca e apreensão na casa do ex-presidente e no Instituto Lula, entre outros lugares ligados ao petista.

Ele foi conduzido coercitivamente pela PF para prestar depoimento, como parte da $24^{\mathrm{a}}$ fase da Operação Lava Jato (FSP, 16/03/2016).

No texto em tela constatamos que os recursos avaliativos, bem como todo o processo persuasivo de forma geral, emergem de maneira velada. Ganha destaque, primeiramente, uma descrição pormenorizada dos fatos que se sucederam no dia anterior, atinentes à gravação autorizada pelo Juiz Sérgio Moro em ação que o ex-presidente é investigado. Segue uma transcrição integral da conversa ora grampeada. Em verdade, passa-se impressão de que os fatos "falam por si mesmos", acionando uma estratégia que permeia toda a matéria em questão e se constitui, por si só, em um meio de prova, mediante a apresentação, nos termos de Perelman e Olbrechts-Tyteca (1996), de uma argumentação calcada na estruturação do real.

No caso específico do texto em análise, a repetição dos acontecimentos vai tecendo uma ilusão de objetividade, o que vem reforçado pela ausência de julgamentos, por parte do enunciador, e pela transcrição da conversa entre os protagonistas. Aliás, a conversa transcrita funciona, em (1), como argumento de autoridade, à medida que se pode deduzir das próprias palavras dos atores políticos em questão - e não do autor do texto - um objetivo oculto subjacente à nomeação, desvelado agora pelo jornal: "Dilma agiu para tentar evitar a prisão de Lula".

Chama a atenção, no entanto, que a posição assumida por aqueles que foram objetos da escuta, questionando a legalidade da operação, venha sempre colocada entre aspas. Na realidade, a descrição essencialmente "factual" tem o potencial de posicionar o leitor para uma avaliação negativa da posição defendida pela parte da Presidente da República e do Ex-Presidente, sobretudo no que concerne às questões de caráter ético e, 
mais especificamente, às condições de sinceridade desses atores, relacionados aos julgamentos de estima e, principalmente, de sansão social.

Nesse sentido, poderíamos afirmar que se estabelece, em relação às estruturas colocadas entre aspas, uma atribuição por distanciamento, indicando tensão e distanciamento entre o posicionamento assumido pelo autor do texto e o discurso citado. Lembremo-nos de que, de acordo com Martin e White (2005), a atribuição está relacionada às formulações em que se atribui a uma fonte externa uma proposição que, em geral, não é assumida pelo enunciador em termos de responsabilidade ou validade modal, ou seja, apresenta o discurso de outros atores sociais como fonte de validade.

A atribuição é subdivida por Martin e White (op. cit.) em reconhecimento e distanciamento. De acordo com os autores, há reconhecimento nos casos em que o enunciador cria uma ilusão de neutralidade no que tange ao seu posicionamento diante do discurso relatado, e distanciamento nos casos em que rejeita tornar-se responsável pela proposição.

Em verdade, conforme se pode perceber em (1) e se poderá notar mais adiante, o discurso relatado assume particular importância para o desencadeamento de diversos mecanismos linguísticos acionados com a finalidade de estabelecer determinados consensos hegemônicos no gênero notícia. Conforme bem aponta Fairclough (1995), a representação do discurso de outrem carrega um processo ideológico cuja relevância deve ser considerada. Analisar em textos quais vozes estão presentes e quais estão ausentes, e as consequências disso para valoração ou depreciação do que foi dito e daqueles que pronunciaram o discurso relatado, pode lançar luz sobre questões de poder e controle no uso da linguagem.

Embora simule uma reprodução transparente do que foi dito ou escrito por outro locutor, o discurso relatado obedece sempre à determinada decisão do jornalista de representar e interpretar as palavras ditas ou escritas em determinado caminho em detrimento de outro. Ademais, o acesso à mídia é mais aberto a alguns setores socialmente dominantes, enquanto "fontes confiáveis" e como "vozes acessadas" que emergem no discurso reportado (cf. HARTLEY, 1982, p. 111 apud FAIRCLOUGH, 1995, p. 63).

Fairclough (1997) destaca ainda que o discurso direto e o indireto apresentam a mesma frequência no noticiário, sendo que o emprego do discurso direto deixa mais clara a decisão, por parte do jornalista, de se associar ou distanciar do discurso citado.

Aliás, na notícia atinente à versão apresentada pela Presidência da República acerca dos fatos em questão, observamos a mesma estratégia de pinçar fragmentos de fala - no mais das vezes em discurso direto - e colocá-las entre aspas, estabelecendo uma estrutura bastante semelhante àquela constatada em (1). Observe:

\section{Dilma diz que fala com Lula em 'teor republicano' e promete ir à Justiça}

O Palácio do Planalto divulgou nota em que apresenta sua versão sobre o telefonema acerca do termo de posse de Luiz Inácio Lula da Silva na Casa Civil e repudia a divulgação do áudio feito pelo juiz Sérgio Moro, de Curitiba. Segundo ela, a iniciativa foi uma "afronta aos direitos e garantias" da Presidência da República.

Segundo o Planalto, Lula iria tomar posse nesta quinta (17), diferentemente do que todos os ministros envolvidos na operação do anúncio de sua entrada no governo vinham falando - a data prevista era de terça-feira (22). Assim, diz a nota, Dilma apenas enviou o termo de posse para Lula assinar, já que sua presença na cerimônia não era certa. A nota não faz referência ao uso "em caso de necessidade" do documento, como a presidente diz na gravação legal da Polícia Federal. "Uma 
vez que o novo ministro, Luiz Inácio Lula da Silva, não sabia ainda se compareceria à cerimônia de posse coletiva [com os novos ministros da Justiça e da Secretaria de Aviação Civil], a presidente encaminhou para sua assinatura o devido termo de posse. Este só seria utilizado caso confirmada a ausência do ministro", afirmou.

"Em que pese o teor republicano da conversa, repudia com veemência sua divulgação que afronta direitos e garantias da Presidência da República. Todas as medidas judiciais e administrativas cabíveis serão adotadas para a reparação da flagrante violação da lei e da Constituição da República, cometida pelo juiz autor do vazamento", diz a nota (FSP, 16/03/2016).

Em (2), a manifestação da voz de outrem emerge sob a forma de uma atribuição por distanciamento, estabelecida já na primeira linha da notícia, em que o autor coloca claramente a posição a seguir como aquela da Presidência, e não a sua ( $O$ Palácio do Planalto divulgou nota em que apresenta sua versão sobre o telefonema acerca do termo de posse). Nesse texto, as avaliações negativas de sanção social acerca do vazamento do grampo e seus responsáveis, inerentes à nota em questão, são colocadas em um contexto mais amplo, de maneira que outras avaliações podem ser negociadas intersubjetivamente, entre o autor do texto e o leitor: em verdade, o autor se utiliza de todas essas estratégias para negociar, com o leitor, um julgamento negativo de sansão social, relacionado a uma suposta falta de honestidade por parte do governo.

Essa outra perspectiva está assentada em um argumento quase-lógico, que denuncia a contradição entre a posição adotada no texto e aquilo que teria sido divulgado anteriormente (Segundo o Planalto, Lula iria tomar posse nesta quinta (17), diferentemente do que todos os ministros envolvidos na operação do anúncio de sua entrada no governo vinham falando - a data prevista era de terça-feira (22)). Assim, ao tomar como foco e matriz as posições assumidas pelo governo, nota-se a busca por apresentar suas contradições e atacar sua credibilidade, reforçando, por conseguinte, a série em favor da publicitação da escuta. Essa ausência de condições de sinceridade vem reforçada pela constatação, explicitada no corpo do texto, de que "a nota não faz referência ao uso 'em caso de necessidade' do documento, "como a presidente diz na gravação legal da Polícia Federal”. Ademais, o texto faz referência direta à suposta legalidade da gravação da Polícia Federal (gravação legal da Polícia Federal).

No entanto, no dia 22 de março, o Supremo Tribunal Federal (STF) se posiciona contra a legalidade da escuta. Há, no noticiário do jornal publicado no dia 23, apenas uma matéria destinada ao tema. Na capa, o título se intitula "Teori Manda Juiz Moro devolver investigação de Lula ao supremo". Observe:

\section{Teori Manda Juiz Moro devolver investigação de Lula ao supremo}

O Ministro do STF Teori Zavascki determinou que o juiz Sérgio Moro envie toda a investigação sobre Lula na Lava a Jato para o Tribunal. O Supremo ainda decidirá de quem é a competência para conduzir a apuração sobre Lula, uma vez que ela alcançou pessoas com foro privilegiado. Teori também colocou o conteúdo dos grampos sob sigilo (FSP, 23/03/2016).

De uma maneira dissimulante, o título e o texto em questão referem-se apenas ao fato de o Ministro do Supremo solicitar a devolução da investigação e de colocar "os conteúdos do grampo sob sigilo", sem fazer referência direta ao episódio principal em torno do qual gravitaria a notícia: o de que a escuta propriamente dita, que ocupou grande parte do noticiário do jornal e que foi considerada pelo mesmo "legal", conforme apontado no exemplo (2), ter tido a sua publicitação considerada ilegal pelo STF. 
Suprimem-se, assim, vozes dissonantes, que apontaram para a ilegalidade da ação e que contestaram a maneira como o juiz e os jornais conduziram o caso.

No dia 29, o Juiz Sérgio Moro viria a pedir desculpas ao STF pela polêmica criada. Na Folha, lê-se a seguinte matéria:

\section{Sérgio Moro pede desculpas ao STF pela polêmica com grampos de Lula}

O juiz Sérgio Moro afirmou ao STF (Supremo Tribunal Federal) que a divulgação dos áudios do ex-presidente Luiz Inácio Lula da Silva - inclusive o telefonema com a presidente Dilma Rousseff - não teve motivação político-partidária nem tinha o objetivo de criar polêmicas ou conflitos.

Moro admite que pode ter errado no entendimento jurídico adotado no caso, mas pede, em três momentos em sua manifestação ao STF, "respeitosas escusas" ao Supremo pelos efeitos causados com a divulgação de escutas telefônicas. Segundo o magistrado, a derrubada do sigilo das escutas feitas pela força-tarefa da Lava Jato foi provocada porque ele avaliou que "não haviam sido alcançadas condutas criminais" das autoridades com foro privilegiado que foram atingidas nas gravações e que só podem ser investigadas com aval do Supremo.

$\mathrm{O}$ juiz defendeu ainda que os áudios revelam que o ex-presidente aparentemente tentou obstruir as investigações da Lava Jato, e demonstra intenção de intimidar autoridades, e que a publicidade "era a melhor maneira de prevenir novas condutas ou tentativas de obstrução ou intimidação da Justiça" pelo petista antes que tomasse posse na Casa Civil.

Moro faz uma avaliação de um por um dos diálogos das autoridades. Sobre as conversas de Lula envolvendo Dilma, o juiz disse que "no momento, de fato, não [foram] percebidos eventuais e possíveis reflexos para a própria Exma. presidente da República". [...]

Moro disse que não havia percebido que a ligação da presidente Dilma para o ex-presidente Lula para falar do termo de posse na Casa Civil foi gravada após o horário definido por ele para as interceptações. [...]

O juiz garante que as autoridades não foram investigadas e que houve encontro fortuito, ou seja, elas aparecem porque ligaram para uma pessoa grampeada e Lula não tinha foro na época. Segundo ministros do STF, o entendimento do tribunal é que se uma determinada investigação detecta que alguém com prerrogativa de foro está praticando crime, a matéria tem que ir para o juiz competente, ou seja, para o Supremo. "Diante da controvérsia decorrente do levantamento do sigilo compreendo que entendimento então adotado possa ser considerado incorreto, ou mesmo sendo correto, possa ter trazido polêmicas e constrangimentos desnecessários. Jamais foi a intenção desse julgador provocar tais efeitos e, por eles, solicito desde logo respeitosas escusas a este Egrégio Supremo", afirmou. "O levantamento do sigilo não teve por objetivo gerar fato político-partidário, polêmicas ou conflitos, algo estranho à função jurisdicional, mas, atendendo ao requerimento do MPF, dar publicidade ao processo e especialmente a condutas relevantes do ponto de vista jurídico e criminal do investigado ex-presidente Luiz Inácio Lula da Silva que podem eventualmente caracterizar obstrução à Justiça ou tentativas de obstrução à Justiça", justificou.

Moro afirmou que é usual levantar o sigilo de gravações após o encerramento da diligência para garantir o contraditório e a publicidade do processo. "O propósito não foi político-partidário, mas sim, além do cumprimento das normas constitucionais da publicidade dos processos e da atividade da Administração Pública, prevenir obstruções ao funcionamento da Justiça e à integridade do sistema judicial frente a interferências indevidas", disse. [...]

A manifestação de Moro foi uma resposta ao pedido de explicações feito pelo ministro Teori Zavascki, relator da Lava Jato no STF. Na semana passada, o ministro considerou a divulgação dos áudios ilegal e determinou que o juiz enviasse as investigações de Lula ao STF para decidir se as apurações vão seguir no Paraná ou no tribunal. Na quinta, o plenário do Supremo deve confirmar a decisão de Teori, pedindo para Moro repassar as apurações.

O ex-presidente é investigado por suposta ocultação de patrimônio e supostos crimes relacionados ao esquema criminoso da Petrobras. A posse de Lula na Casa Civil continua suspensa por determinação de uma decisão liminar do ministro Gilmar Mendes (FSP, 29/03/2016).

Cumpre destacar, primeiramente, que o texto em questão integra apenas a versão on-line do Jornal. Na versão impressa, por aquele período, a Folha de S. Paulo não fez mais referência ao episódio. 
No que diz respeito ao texto propriamente dito, é importante observar que se atribui ao próprio juiz Sérgio Moro o papel de qualificar sua atuação no episódio das escutas envolvendo a Presidente e o Ex-Presidente da República, mediante diversas estruturas interpessoais de "engajamento" por "atribuição". Essa nova estrutura contrapõe-se àquelas observadas em (1) e (2), em que a voz autoral distanciava-se da posição enunciativa assumida. Mediante o emprego ora do discurso direto, ora do discurso indireto, ora do discurso indireto livre, a voz do juiz "funde-se" à do jornal em (4), mobilizando, no plano das relações interpessoais, a "incorporação" (cf. FAIRCLOUGH, 1995, p. 58), do discurso de Sérgio Moro.

Nos termos de Martin e White (op. cit.), esses recursos funcionam como estratégias de engajamento por "concordância", mediante o "endosso" das declarações do juiz. No plano argumentativo, instala-se uma argumentação calcada na estrutura do real, em que as posições assumidas pelo juiz Moro são alçadas ao plano de argumentos de autoridade.

O conjunto de julgamentos negativos de sanção social apresentados, relacionados à falta de compromisso dos atores da gravação com a veracidade (grau de honestidade ou sinceridade) e propriedade (grau de transparência ética) dos investigados, ( $O$ juiz defendeu ainda que os áudios revelam que o ex-presidente aparentemente tentou obstruir as investigações da Lava Jato, e demonstra intenção de intimidar autoridades, e que a publicidade "era a melhor maneira de prevenir novas condutas ou tentativas de obstrução ou intimidação da Justiça" pelo petista antes que tomasse posse na Casa Civil), assenta-se em argumentos baseados na estrutura do real, mediante diversas relações de causa e efeito que justificam, como pano de fundo, a atuação do enunciador, em detrimento da reprimenda do STF.

Em verdade, conforme se pode observar, a notícia em questão não trata propriamente do pedido de desculpas do juiz, mas oferece espaço para que o mesmo se defenda ante o STF e os leitores do Jornal. É por meio do conjunto de argumentos apresentados por Moro que se sustenta, em última análise, a posição da própria Folha de S. Paulo - que tratou de qualificar como "legal" a escuta, conforme observamos em (2) e que certamente está colocada agora como corresponsável pela divulgação de uma escuta ilegal e, portanto, passível de uma sansão social.

A onipresença da voz do juiz Moro universaliza uma perspectiva particular e se contrapõe à supressão de vozes dissonantes, que contestaram a divulgação do áudio e defenderam a ilegalidade dessa ação, estabelecendo um determinado consenso hegemônico (cf. RAMALHO; RESENDE, 2006) em favor da divulgação e contrário à nomeação de Lula para a Casa Civil - e, por conseguinte, às atitudes do Governo da Presidente Dilma Rousseff. E porque não dizer: a adoção dessa perspectiva em uníssono, em detrimento dos direitos daqueles que foram o alvo da operação, encaminha o leitor, em um plano maior de generalidade, para o posicionamento em favor da necessidade do afastamento da Presidente da República.

\section{Conclusões}

Utilizando um material para análise representativo, ainda que de maneira por demais sucinta, do noticiário político contemporâneo, foi possível constatar, com a análise dos dados, no que se refere aos pontos de contato entre a Análise Crítica do 
Discurso e a Retórica, que os mecanismos linguísticos acionados para o estabelecimento das relações interpessoais apresentados por Martin e White (op. cit.) assumem, em grande parte, o papel de ancorar o desenvolvimento das estratégias argumentativas, em especial os argumentos baseados na estrutura do real, como o argumento pragmático e, sobretudo, o argumento de autoridade. Essa constatação ratifica a ênfase dada por Fairclough (1997) ao discurso citado no noticiário, com suas formas peculiares de instaurar determinados tipos de controles ideológicos e consensos hegemônicos.

No que tange à análise dos recursos interpessoais empregados e suas respectivas formas da persuasão, podemos afirmar que a suposta posição crítico-heurística que as mídias reivindicam para si, de "deslindar o obtuso", de "revelar o real", de ser "portavoz" daqueles que estão impossibilitados de agir efetivamente no espaço político, reserva ao noticiário um espaço privilegiado para o exercício do poder e controle ideológico sobre as classes dominadas.

Mediante a análise dos textos, fica ainda patente que o discurso citado e, por conseguinte, o argumento de autoridade permeiam o gênero notícia, e ainda que nem de longe pode-se atribuir como característica do noticiário contemporâneo o "relato objetivo dos acontecimentos recentes". Na realidade, a ilusão da objetividade é construída mediante estratégias camufladas de persuasão e controle, as quais puderam ser verificadas com a breve análise dos recursos interpessoais e dos tipos de argumentos empregados. Ratifica-se, assim, a posição de Van Dijk (2008) de acordo com a qual, nas sociedades modernas, o poder exercido pelos jornais inclui maneiras mais sutis de influenciar, o que é obtido por meio do controle da quantidade e do tipo de informação.

Nesse sentido, os grandes conglomerados que detêm o controle das agências midiáticas têm o poder de determinar a agenda da discussão pública, a relevância dos tópicos e, sobretudo, de qual maneira cada ator político deve ganhar espaço.

\section{REFERÊNCIAS}

BOURDIEU, P. Outline of a theory of pratic. Cambridge: Cambridge University, 1991.

CASTELLS, M. A era da informação: economia, sociedade e cultura. Tradução de Klauss Gerhardt. 6. ed. São Paulo: Paz e Terra, 2008.

COURTINE, J. J. Os deslizamentos do espetáculo político. In: GREGOLIN, M. R. V. (Org.). Discurso e mídia: a cultura do espetáculo. São Carlos: Claraluz, 2003. p. 49-66.

CHARAUDEAU, P. O discurso das mídias. São Paulo: Contexto, 2006.

FAIRCLOUGH, N. Critical Discourse Analysis: the critical study of language. London and New York: Longman, 1995.

. Critical Discourse Analysis: papers in the critical study of language. London and New York: Longman, 1997.

. Discurso e mudança social. Brasília: Editora da Universidade de Brasília, 2001. 2007. . Analysing Discourse: textual analysis for social research. London: Routledge,

HALLIDAY, M. A. K. An Introduction to functional grammar. London: Hodder Arnold, 2001. 
HABERMAS, J. The theory of communicative action. Reason and the rationalizalion of society. Boston: Beacon Press, 1984.

LIMA, F. F. Persuasão e constituição de consensos na mídia impressa paulista: o noticiário sobre as eleições. 2013. 259 f. Relatório Final de Pós-Doutoramento Faculdade de Filosofia, Letras e Ciências Humanas, Universidade de São Paulo, São Paulo, 2013.

MARSHALL, L. O jornalismo na era da publicidade. São Paulo: Summus Editorial, 2003.

MARTIN, J. R.; WHITE, P. R. R. The language of evaluation: appraisal in English. New York/Hampshire: Palgrave Macmillan, 2005.

PIOVEZANI FILHO, C. F. Política midiatizada e mídia politizada: fronteiras mitigadas na pós-modernidade. In: GREGOLIN, M. R. V. (Org.). Discurso e mídia: a cultura do espetáculo. São Carlos: Claraluz, 2003. p. 49-64.

PERELMAN, C.; OLBRECHTS-TYTECA, L. O tratado da argumentação: a nova retórica. São Paulo: Martins Fontes, 1996.

RAMALHO, V.; RESENDE, V. M. Análise de discurso crítica. São Paulo: Contexto, 2006.

THOMPSON, J. Mídia e modernidade: uma teoria social da mídia. 10. ed. Petrópolis: Editora Vozes, 1998.

VAN DIJK, T. A. Discurso, poder y cognición social. Cuadernos, 2, Año 2. Maestría en Lingüística. Escuela de Ciencia del Lenguaje y Literaturas. 1994. Disponível em $<$ www.discursos.org/Art/Discurso,\%20poder\%20y\%20cognici\%F3n\%20social.pdf $>$. Acesso em: 6 jun. 2007.

Discurso e poder. São Paulo: Contexto, 2008.

WHITE, P. Valoração: a linguagem da avaliação e da perspectiva. Linguagem em (Dis)curso, Tubarão, v. 4, n. esp., p. 178-205, 2004.

WODAK, R. Do que trata a ACD: um resumo de sua história, conceitos importantes e seus desenvolvimentos. Linguagem em (Dis)curso, Tubarão, v. 4, n. esp., p. 223-243, 2004.

Recebido em: 15/08/2016

Aprovado em: 06/06/2017 